\title{
Association of Cardiovascular Disease with the Metabolic Syndrome in a Predominantly Male Cohort with Rheumatoid Arthritis
}

\author{
G.S. Kerr ${ }^{1}$ et al.* \\ 1Washington DC Veterans Affairs Medical Center \\ and Georgetown University, Washington, DC
}

USA

\section{Introduction}

Despite the therapeutic advances in RA that have led to reduced pain, joint destruction and disability, as many as $50 \%$ of patients are at risk of death from a cardiovascular event (Maradit-Kremers et al., 2005; Stevens et al., 2005). Inexplicable by the usual traditional risk factors, the accelerated atherosclerosis (Gaonzalez-Gay et al., 2005) has been postulated to result from the increased systemic inflammatory burden of rheumatoid disease (Del Rincon et al., 2001; Gabriel et al., 1999; Kremers \& Gabriel, 2006; McEntegart et al., 2001).

The metabolic syndrome (MetS) is a composite diagnosis, combining phenotypic features that portend an increased risk for cardiovascular disease (CVD). The syndrome consists of visceral obesity, atherogenic dyslipidemia, hypertension, and impaired fasting glucose/glucose tolerance test or overt diabetes mellitus (DM) (National Cholesterol Education Program, 2001). Studies have reported the presence of MetS to be associated with an approximate 2- fold increased risk for incident cardiovascular morbidity and mortality (Lakka et al., 2002), a 2.1 fold increase for initial stroke (Najarian et al., 2006), and 3.5 fold increased risk for Type II DM (Lorenzo et al., 2003). The complex interplay of genetic and environmental factors, insulin resistance and inflammation, are all believed to contribute to the pathogenesis of the syndrome.

The overall prevalence of MetS in the US population, as evaluated by the National Health and Nutrition Examination Survey (NHANES III), is $23.1 \%$, and increases with age to as high as $44 \%$ in those 65 years or older (Ford et al., 2002). Several studies have established an increased prevalence of insulin resistance and increased risk for CVD in RA patients (Dessein et al., 2002a, 2002b). However, there are few reports regarding MetS in RA, and the

\footnotetext{
${ }^{*}$ I. Sabahi'1, J.S. Richards'1, T.R. Mikuls², B.V. Rangan³, A. Reimold³, G.W. Cannon',

D. Johnson ${ }^{5}$ and L. Caplan ${ }^{6}$

${ }^{2}$ Omaha Veterans Affairs and University of Omaha, Omaha, NE, USA

${ }^{3}$ Dallas Veterans Affairs and University of Texas Southwestern, Dallas, TX, USA

${ }^{4}$ George E. Wahlen Veterans Affairs and University of Utah, Salt Lake City, UT, USA

5 Jackson Veterans Affairs and University of Mississippi, Jackson, MS, USA

${ }^{6}$ Denver Veterans Affairs and University of Colorado, Denver, CO, USA
} 
existing data reflect variations in the populations studied (Crowson et al., 2011; Karvounaris et al., 2007). Data from Europe and the US have shown associations between the syndrome and the inflammatory burden of RA.

Most data on RA, including reports related to MetS and CVD, are comprised mainly of females. The few reports on RA in males indicate a more severe course of disease, and worse outcome (Ford et al., 2002; Janghorbani et al., 1993; Jawaheer et al., 2006; Mikuls et al., 2011). Further, elderly males more often have comorbid diseases such as diabetes mellitus and hypertension that places them at even greater risk for CVD.

Therefore we sought to examine the prevalence and relationship of MetS to RA disease burden and CVD in a primarily elderly, male RA cohort.

\section{Patients and methods}

\subsection{Study population}

Study patients enrolled in the ongoing Veterans Affairs Rheumatoid Arthritis (VARA) Registry prior to January 2009 were included in the study. The characteristics of this population have been previously described (Mikuls et al., 2007). Briefly, VARA is a multicenter chronic disease registry initiated in 2003 now including collection sites at VA Medical Centers across the U.S. The current study included participants from VA sites in Dallas, Denver, Jackson, Omaha, Salt Lake City, and Washington, DC. Rheumatoid arthritis (RA) patients with disease onset after age 18 years who fulfill American College of Rheumatology (ACR) classification criteria for RA (Arnett et al., 1988) are invited to enroll. Participating sites prospectively collect and archive clinical and laboratory observations associated with RA during routine visits and standard of care. VARA has been approved by the Institutional Review Board (IRB) and VA Research and Development Committee at each participating site. All subjects provide written consent for a single blood draw and ongoing review of their electronic medical records.

\subsection{Metabolic syndrome definition}

The NCEP/ATPIII criteria (National Cholesterol Education Program, 2001) for MetS were modified so that a body mass index (BMI) of $\geq 30 \mathrm{~kg} / \mathrm{m}^{2}$ replaced waist/hip circumference. Because waist and hip measurements are not routinely available on study subjects, BMI was used as a surrogate for waist-to-hip circumference with the following rationale: a) weight and annual height measurements are routinely obtained on all our patients, b) data support BMI to be as accurate as waist circumference in identifying individuals for risk of CVD (Farin et al, 2006), c) BMI is included in the WHO definition for MetS (World Health Organization [WHO], 1999) and there appears to be at least modest levels of agreement between BMI and waist-tohip ratio in both men and women (Balkau et al., 2006), and d) to obviate the varied cut off points for waist circumference for different ethnic groups (Alberti et al., 2005). Additionally, documented prior use of disease specific medications were used as surrogates for the other three MetS components. Hence MetS was defined as presence of $\geq 3$ of 4 criteria (BMI $\geq 30$ $\mathrm{kg} / \mathrm{m}^{2}$, anti-hypertensive, lipid lowering, and/or diabetes agents) (Grundy et al., 2005).

\subsection{Clinical measures}

RA disease severity was assessed by rheumatoid factor (RF) positivity, duration of disease, presence of radiographic changes suggestive of RA (based on ACR criteria) and nodules at enrollment. Disease activity was assessed at the time of the most recent clinic visit by 
erythrocyte sedimentation rate (ESR), C-reactive protein (CRP), total swollen and tender joint count (0-28 joints), patient global well-being $100 \mathrm{~mm}$ visual analog scale, modified health assessment questionnaire (MD-HAQ, 0-3) and three-variable Disease Activity Score (DAS28-3v; a composite measure based on swollen/tender joint counts and ESR) (Bawa et al., 2005; Prevoo et al., 1995). The three-variable DAS was used in place of a four variable DAS to minimize the impact of missing data from patient global scores.

Disease-modifying anti-rheumatic therapy (DMARD), biologic treatments, and prednisone use were also recorded at the most recent visit. DMARD agents included methotrexate, sulfasalazine, hydroxychloroquine, and leflunomide; biologic treatments included antitumor necrosis factor (adalimumab, etanercept, infliximab), anti-signal 2 inhibitor (abatacept) and anti-CD20 (rituximab) agents. Patient report of ever or never smoking was tabulated, and subjects were categorized based on a history of CVD (documentation of prior coronary artery disease, myocardial infarction, angina, cerebrovascular event, transient ischemic attack, or peripheral vascular disease).

\subsection{Statistical analysis}

Descriptive statistics were used to define the group. Group comparisons, based on the presence/absence of MetS, were performed using Chi-square for categorical variables and a one-way ANOVA for continuous data. Odds ratios (OR) and 95\% confidence intervals were used to assess the association of MetS with prevalent CVD and were calculated using multivariable logistic regression, adjusting for age, sex, smoking status (ever vs. never), and the current use of DMARDs and/or biologic therapies. Given the reported antiinflammatory effect of select lipid lowering agents (statins) in RA, we performed a subanalysis in subjects with MetS to examine the association of statin use with measures of disease activity. All analyses were performed using SAS (SAS Inc, Cary, NC).

\section{Results}

Six-hundred seventy-one patients were included in this study (Table 1). The study cohort included $53(7.9 \%)$ women, had a mean age of 65.4 years [SD10.8], and a mean disease duration of 13.7 years [SD 11.5]. The majority were Caucasian $(n=543,80.9 \%)$. Four hundred and twelve (61.4\%) had radiographic changes consistent with RA, and $312(46.5 \%)$ had nodules. Approximately 58.3\% were on a traditional DMARD at their most recent clinic visit, while an additional $25.8 \%$ were receiving a combination of a biologic agent with a traditional DMARD. Fifty three percent of the study cohort was receiving prednisone.

The mean DAS28 was 3.2 [SD 1.3] and CRP was 1.3 [SD 1.9] mg/dl. The majority $(78.8 \%)$ were either previous or current smokers. One-hundred eighty-nine subjects satisfied the modified criteria for MetS, corresponding to a prevalence of $28.2 \%$ (95 \% CI 24.7-31.7). There were no significant differences in subject demographics, measures of disease severity or activity, use of biologic agents or DMARDS, prednisone use, or smoking status in RA subjects with MetS compared to those without MetS (Table 1). In a subanalysis of subjects with and without MetS, there were no significant differences in measures of disease activity in those taking statins compared to individuals not taking statins (data not shown). As expected, disease components of MetS were far more common in those with the syndrome in comparison to those without MetS (Figure 1). Of note, a BMI that exceeded $30 \mathrm{~kg} / \mathrm{m}^{2}$ was present in only one-third of study patients, but comprised $66 \%$ of MetS patients and only $20 \%$ of individuals without MetS. The use of anti-hypertensive and lipid lowering agents 
were nearly universal among those meeting criteria for MetS, with over 95\% use. Logistic regression analysis revealed MetS to be associated with an approximately three-fold risk of CVD (OR=2.9; 95\% CI 1.95-4.34), after adjusting for age, sex, DMARD / biologic use, and smoking status (Table 2). There was no increased CVD risk with individual components of the metabolic syndrome.

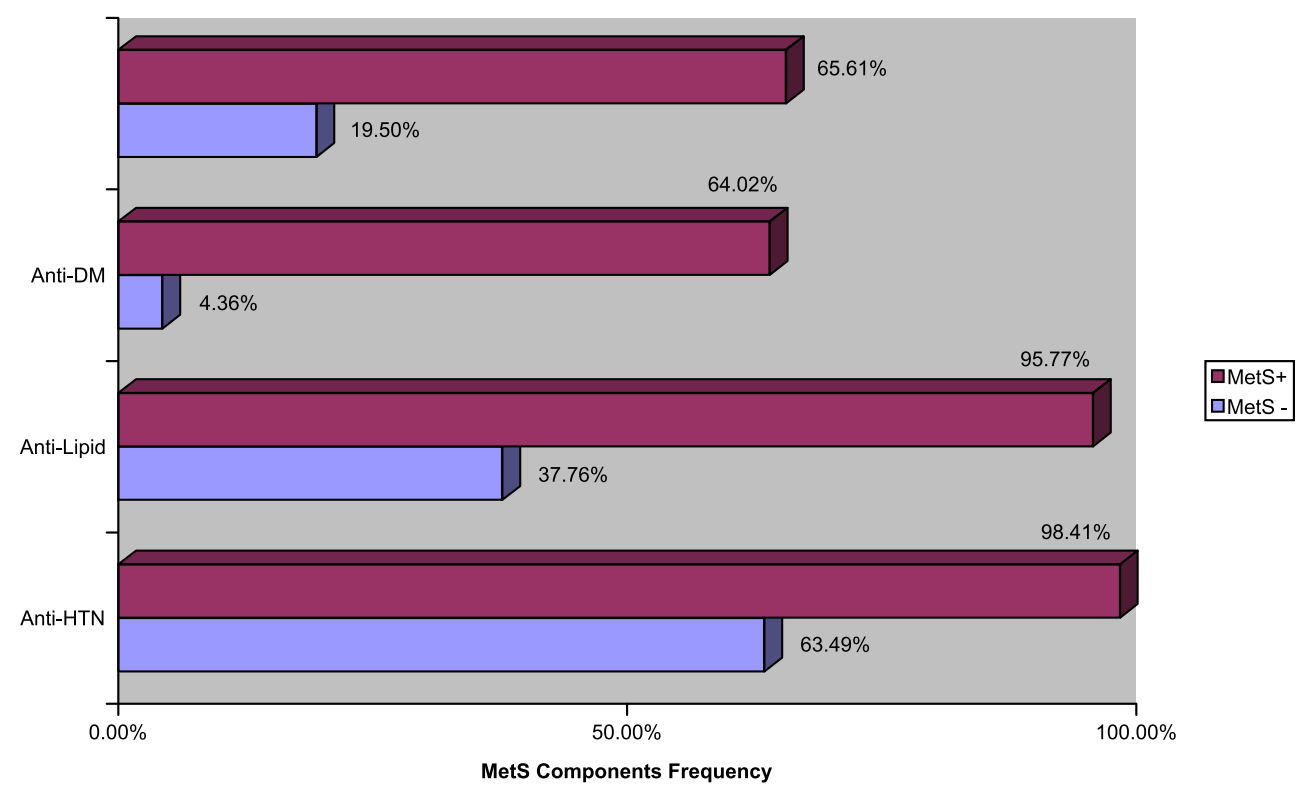

MetS $=$ Metabolic Syndrome

BMI = Body Mass Index

Anti-DM = Treatment for diabetes with insulin and/or oral hypoglycemic medications

Anti-Lipid $=$ Treatment for dyslipidemia with cholesterol lowering medications

Anti-HTN = Treatment for high blood pressure with medications

Fig. 1. MetS Components Frequency in VARA cohort

\section{Discussion}

In our cohort, the prevalence of MetS was $28.2 \%$ and had significant association with CVD. The few existing studies that have examined the relationship of RA with MetS primarily involved women, and indicated increased mortality from CVD among those satisfying criteria for MetS. Men with RA have more extra-articular disease and a greater overall mortality (Janghorbani et al., 1993; Jawaheer et al., 2006; Mikuls et al., 2011). In general, there is a disproportionate individual impact of MetS, CVD, and RA in men. Our findings provide data previously lacking regarding the frequency of MetS in older men with RA and its relationship with RA-specific factors and CVD co-morbidity.

In non-RA populations, MetS has been reported to increase the risk for CVD by two fold, and death by as much as 4 fold (Dekker et al., 2005; Lakka et al., 2002). In a Finnish cohort of men aged 42 to 60 years of age, MetS was found in only $14.3 \%$, but with a 2.9 to 4.3 greater risk of death from coronary heart disease (Lakka et al., 2002). In a population-based cohort 


\begin{tabular}{l|ccc}
\multicolumn{4}{c}{ VARA Cohort } \\
\multicolumn{4}{c}{$\%(n)$, mean [SD] } \\
Variables & $\%$ (Number) & MetS Absent & MetS Present \\
Age & $(\mathrm{N}=671)$ & $78 \%(482)$ & $28 \%(189)$ \\
Female & $65.35[$ SD 10.75] & $65.23[$ SD11.43] & $65.66[8.79]$ \\
Caucasian & $7.9(53)$ & $9.8(47)$ & $3.2(7)$ \\
African American & $80.6(543)$ & $80.3(387)$ & $82.5(156)$ \\
Erosions present & $14.6(98)$ & $15.4(74)$ & $12.7(24)$ \\
Disease Duratio & $61.4(412)$ & $63.9(308)$ & $55(104)$ \\
Nodules present & $13.74[$ SD 11.5] & $14.08[$ SD 11.61] & $12.89[$ SD 11.21] \\
RF Positive & $46.5(312)$ & $47.5(229)$ & $43.9(83)$ \\
DAS28(3v) & $88.4(593)$ & $89(429)$ & $86.8(164)$ \\
CRP & $3.20[$ SD 1.34] & $3.21[$ SD 1.33] & $3.18[$ SD 1.38] \\
DMARDS & $1.29[$ SD 1.87] & $1.37[$ SD 1.98] & $1.09[$ SD 1.53] \\
DMARDS+Biologic & $58.3(391)$ & $56.2(271)$ & $63.5(120)$ \\
Prednisone & $25.8(173)$ & $26.4(127)$ & $24.3(46)$ \\
Ever Smoke & $43.5(292)$ & $46.7(225)$ & $35.5(67)$ \\
\hline
\end{tabular}

$P$ values not statically significant for all variables

$\mathbb{1}$ Veteran Affairs Rhematoid Arthritis Registry

MetS $=$ Metabolic Syndrome DMARDS=Disease-Modifying Anti-Rheumatic Drugs

*Biological Agents (mainly anti-tumor necrosis factor) tDisease Activity Score, 28 joints

$\mathrm{SD}=$ Standard Deviation

Table 1. Demographics and Parameters of Disease Severity and Activity of Veterans Affairs Rheumatoid Arthritis Patients with and without the Metabolic Syndrome

\begin{tabular}{l|cccc}
\hline Variables & OR & \multicolumn{2}{c}{$95 \%$ C.I. } & P value \\
\cline { 3 - 4 } MetS Present & & Lower & Upper & \\
DMARDS & 2.91 & 1.95 & 4.34 & $<0.001$ \\
Age & 2.27 & 1.47 & 3.50 & $<0.001$ \\
Ever Smoking & 1.04 & 1.02 & 1.07 & $<0.001$ \\
Gender (male) & 1.67 & 0.99 & 2.82 & 0.05 \\
DMARDS+Biologic* & 0.38 & 0.11 & 1.29 & 0.12 \\
\hline
\end{tabular}

DMARDS (Disease Modifying Anti-rheumatic drugs)

*Biologic Agents (mainly anti-tumor necrosis factor)

$\mathrm{CI}=$ Confidence Interval

Table 2. Multivariable Logistic Regression Model examining the association of Metabolic Syndrome with Cardiovascular Disease in VARA cohort

of 615 men aged 50 to 75 years, the prevalence of MetS varied from 17\% - 32\% when assessing the agreement in the various definitions of MetS (Dekker et al., 2005). When using NCEP-ATPIII criteria, the hazard ratio for fatal and non-fatal CVD in men with MetS was 1.91 (1.31-2.79), compared to 1.68 (1.11-2.55) in the 749 women.

A similar risk for CVD occurs for RA patients with MetS, but these results are obtained from cohorts consisting primarily of female patients (Dessein et al., 2002; Karvounaris et al., 2007). 
Further, as in the non-RA study cohorts, the definitions and criteria of both MetS and CVD varied. In one study, MetS, as defined by WHO criteria, was a better predictor of coronary calcification than NCEP-ATPIII criteria (Pandya et al., 2006). Though coronary calcification detection by electron beam computer tomography is a more sensitive means of detecting atherosclerosis than clinical diagnoses, the association with MetS achieved an odds ratio of 2.02, (95\% CI: 1.03-3.97, p=0.04.), less than the 2.91 (95\% CI: 1.95-4.34, p<0.001) in our cohort. In that study (Pandya et al, 2006), almost $50 \%$ of the patients had longstanding disease (median $=20$ years), were younger than our cohort (median 59 years), and were majority female. The almost three-fold risk for CVD in our cohort was independent of anti-rheumatic treatment, smoking, age or gender. There was, however, a trend to increased risk with increasing age and DMARD therapy alone, the latter perhaps related to channeling bias or confounding by indication.

Given the notable comorbidity in our study population, and the historically age-matched prevalence of MetS in $44 \%$ of the US NHANES III population aged 65 years, our prevalence of $28 \%$ was unexpected. The limited data from other disease cohorts involving U.S. veteran populations report higher frequencies on the order of 50\% (Meyer et al., 2006; Pandya et al., 2006). However, our results are similar to another US RA cohort, $40 \%$ of whom were male. The prevalence of MetS was approximately $26 \%$ as defined by NCEP-ATPIII criteria, and was almost half that of controls (Rodriguez-Pla et al., 2007). In that study, the difference in prevalence between RA and controls could not be explained by differences in physical activity. In contrast, in 200 similarly aged but primarily female RA patients, MetS occurred in $44 \%$ of patients at a similar rate to the age- and sex- matched controls, but used ATPIII criteria (National Cholesterol Education Program, 2001). Of the 53 men in the study, approximately $30 \%$ with MetS had coronary disease $(p=0.02)$. Not only do differences in MetS classifications make comparisons amongst cohorts difficult, but the disparate muscle loss with fat retention that occurs in RA patients, affects BMI assessments. Rheumatoid cachexia, which is present in most (two-thirds) RA patients, doesn't merely involve fat "retention"; there is exacerbated fat gain. When body composition is assessed (i.e. \% body fat), up to $80 \%$ of RA patients satisfy BMI criteria for obesity i.e. $\geq 27 \%$ for males, and $\geq 38 \%$ for females (Baumgartner et al., 1999). This prevalence of obesity in RA is not reflected by BMI because of the concomitant loss of muscle. Thus, for individuals with the same BMI, an RA patient will have, on average, $4.3 \%$ higher \% body fat than a healthy, age- and sexmatched subject. Therefore, in RA patients, a BMI greater than $28 \mathrm{~kg} / \mathrm{m}^{2}$ has been proposed to define obesity, and may, and may therefore lead to higher, and more accurate, estimations of MetS in RA cohorts. (Stavropoulos-Kalinoglou et al., 2007).

Our modified definition of MetS based on NCEP-ATPIII criteria though highly specific, may have lacked sensitivity by excluding otherwise eligible patients with discordance between waist-to-hip ratio and BMI, or those who had not received pharmacological treatment for component diseases. We recognize therefore that our prevalence estimate may have trended towards the conservative and underestimated the true impact of MetS in this population; an important concern given the strong association between MetS and CVD. However, of note is the rigor with which VA patients are screened and treated for diabetes mellitus, hypertension and hyperlipidemia based on adherence to select process indicators (Steven, 2004). Therefore it is likely that our use of medication is a reasonable surrogate for the select comorbidities of MetS. Surprisingly, our study found no significant risk of any of the individual components of MetS, and may indicate that traditional risk factors do not impart the same risk for CVD in RA as in the general population. 
The role of adipose tissue and BMI in inflammatory disease is evolving as is its impact on response to disease-modifying therapies (Klaasen et al., 2011; Ouchi et al., 2011). Yet the association of MetS with RA disease activity and severity is equivocal. One study has reported an increase of nine-fold in odds ratio correlation between MetS and disease activity, but not with severity (Karvounaris et al., 2007). A relationship between MetS and disease activity and severity was not found in our cohort, but the mean disease activity was low and the effect of DMARD therapies on MetS is unknown. Aware that statin use may be more frequent in the context of MetS and of its potential anti-inflammatory and immunomodulatory effects, we explored but were unable to find an association between statin use and disease activity in RA patients with and without MetS.

There are limitations to our study. The use of BMI in place of waist-to-hip circumference may have limited the sensitivity of our criteria. However, the use of BMI in lieu of waist-tohip circumference allows pragmatic application in clinical practice, and thereby easier identification of MetS. There is a reported positive correlation between BMI and CVD and increased CRP levels, and BMI is inversely related to functional status in inflammatory rheumatic diseases (Choi et al., 2002; Kremer \& Reed, 2006). There was no difference in disease activity amongst the cohort, and the increased risk for CVD in RA patients with MetS was independent of disease activity. Whether a lower DAS score is found in RA patients with MetS, regardless of traditional or biologic DMARD, remains to be determined. Strengths of the study include that it is of a well-characterized group of males with RA, a group that to date has been vastly underrepresented in clinical research. Moreover, the patients treated at these sites have equal access to medical care and RA therapies, hence providing the unique opportunity to explore disease related outcomes in a uniform health system. Although premature atherosclerosis occurs in RA independent of traditional risk factors, our findings indicate that it is the composite entity of the metabolic syndrome rather than its individual components that pose the risk for CVD. Optimum control of all individual components is required to minimize cardiovascular morbidity.

\section{Acknowledgement}

Jeffrey Huang, Research Assistant, for manuscript preparation and literature review.

\section{References}

Alberti KG, Zimmet P, Shaw J, for the IDF Epidemiology Task Force Consensus Group. The metabolic syndrome--a new worldwide definition. Lancet 2005;366:1059-1062.

Arnett FC, Edworthy SM, Bloch DA, et al. The American Rheumatism Association 1987 revised criteria for the classification of rheumatoid arthritis. Arthritis and Rheum, 1988 Mar;31(3):315-24.

Balkau B, Sapinho D, Petrella A, et al. D.E.S.I.R. Study Group. Prescreening tools for diabetes and obesity-associated dyslipidaemia: comparing BMI, waist and waist hip ratio. The D.E.S.I.R. Study. Eur J Clin Nutr. 2006 Mar;60(3):295-304.

Baumgartner et al., 1999, Am J Epidemiol 147:755-763

Bawa, S, Fowler L, Bradlow A. Comparison between DAS 284 Score \& 3 Score- Would it influence patient eligibility for, or evaluation of response to Anti-TNF alpha? British Society for Rheumatology Annual Meeting, 19-22 April 2005. Supplement 1:i99. 2005 March 
Choi HK, Hernan MA, Seeger JD, et al. Methotrexate and mortality in patients with rheumatoid arthritis: a prospective study. Lancet. 2002 Apr 6;359(9313):1173-7.

Chung CP, Oeser A, Solus JF, et al. Prevalence of metabolic syndrome is increased in rheumatoid arthritis and is associated with coronary atherosclerosis. Atherosclerosis 2008;196:756-763

Crowson CS, Myasoedova E, Davis JM 3rd, Matteson EL, Roger VL, Therneau TM, FitzGibbon P, Rodeheffer RJ, Gabriel SE. Increased prevalence of metabolic syndrome associated with rheumatoid arthritis in patients without clinical cardiovascular disease. J Rheumatol. 2011 Jan;38(1):29-35.

Dekker JM, Girman C, Rhodes T, et al. Metabolic syndrome and 10-year cardiovascular disease risk in the Hoorn Study. Circulation. 2005;112:666-73.

Del Rincon ID, Williams K, Stern MP, et al. High incidence of cardiovascular events in a rheumatoid arthritis cohort not explained by traditional cardiac risk factors. Arthritis Rheum. 2001;44:2737-45.

Dessein PH, Joffe BI, Stanwix A, et al. The acute phase response does not fully predict the presence of insulin resistance and dyslipidemia in inflammatory arthritis. $J$ Rheumatol. 2002;29:462-6.

Dessein PH, Stanwix AE, Joffe BI. Cardiovascular risk in rheumatoid arthritis versus osteoarthritis: acute phase response related decreased insulin sensitivity and highdensity lipoprotein cholesterol as well as clustering of metabolic syndrome features in rheumatoid arthritis. Arthritis Res. 2002;4:R5.

Expert Panel on Detection, Evaluation, and Treatment of High Blood Cholesterol in Adults. Executive summary of the third report of the National Cholesterol Education Program (NCEP) Expert Panel on Detection, Evaluation, and Treatment of High Blood Cholesterol in Adults (Adult Treatment Panel III). JAMA. 2001;285:2486-2497.

Expert Panel on Detection, Evaluation, and Treatment of High Blood Cholesterol in Adults. Executive summary of the third report of the National Cholesterol Education Program (NCEP) Expert Panel on Detection, Evaluation, and Treatment of High Blood Cholesterol in Adults (Adult Treatment Panel III). JAMA. 2001;285:2486-2497

Farin HM, Abbasi F, Reaven GM. Comparison of body mass index versus waist circumference with the metabolic changes that increase the risk of cardiovascular disease in insulin-resistant individuals. Am J Cardiol. 2006;98(8):1053-6.

Ford ES, Giles WH, Dietz WH. Prevalence of the metabolic syndrome among US adults: findings from the third National Health and Nutrition Examination Survey. JAMA. 2002;287:356-359.

Gabriel SE, Crowson CS, O'Fallon WM. A comparison of two comorbidity instruments in arthritis. J Clin Epidemiol. 1999 Dec;52(12):1137-42.

Gonzalez-Gay MA, Gonzalez-Juanatey C, Martin J. Rheumatoid arthritis: a disease associated with accelerated atherogenesis. Semin Arthritis Rheum. 2005 Aug;35(1):817.

Grundy SM, Cleeman JI, Daniels SR, Donato KA, Eckel RH, Franklin BA, Gordon DJ, Krauss RM, Savage PJ, Smith SC Jr, Spertus JA, Costa F. Diagnosis and management of the metabolic syndrome: an American Heart Association/National Heart, Lung, and Blood Institute Scientific Statement. Circulation 2005;112:2735-2752.

Janghorbani M, Hedley AJ, Jones RB. Gender Differential in All-Cause and Cardiovascular Disease Mortality. Int. J. Epidemiol.1993;22:1056-1063 
Jawaheer D, Lum RF, Gregersen PK, et al. Influence of male sex on disease phenotype in familial rheumatoid arthritis. Arthritis Rheum. 2006 Oct;54(10):3087-94

Karvounaris SA, Sidiropoulos PI, Papadakis JA, et al. Metabolic syndrome is common among middle-to-older aged Mediterranean patients with rheumatoid arthritis and correlates with disease activity: a retrospective, crosssectional, controlled, study. Ann Rheum Dis. 2007;66:28-33.

Klaasen R, Wijbrandts CA, Gerlag DM, Tak PP. Body mass index and clinical response to infliximab in rheumatoid arthritis. Arthritis Rheum 2011;63:359-64

Kremer JM , Reed G. Obesity is an Independent Contributor to Functional Capacity and Inflammation in Rheumatoid Arthritis and Psoriatic Arthritis. Presented at EULAR 2006 Meeting; June 21-24, 2006, Amsterdam, Netherlands.

Kremers HM, Gabriel SE. Rheumatoid arthritis and the heart. Curr Heart Fail Rep. 2006 Jun;3(2):57-63

Lakka HM, Laaksonen DE, Lakka TA, et al. The Metabolic Syndrome and Total and Cardiovascular Disease Mortality in Middle-aged Men. JAMA. 2002;288:2709-2716

Lorenzo C, Okoloise M, Williams K, et al. The metabolic syndrome as predictor of type 2 diabetes: the San Antonio Heart Study. Diabetes Care. 2003;26:3153-3159.

Maradit-Kremers H, Nicola PJ, Crowson CS, Ballman KV, et al. Cardiovascular death in rheumatoid arthritis: A population-based study. Arthritis Rheum. 2005 Mar; 52(3):722-32.

McEntegart A, Capell HA, Creran D, et al. Cardiovascular risk factors, including thrombotic variables, in a population with rheumatoid arthritis. Rheumatology (Oxford). 2001;40:640-4.

Meyer, J. Loh, C, Leckband SG, et al. Prevalence of the metabolic syndrome in veterans with schizophrenia. J. Psychiatr Pract. 2006 Jan;12(1):5-10

Mikuls TR, Fay BT, Michaud K, Sayles H, Thiele GM, Caplan L, Johnson D, Richards JS, Kerr GS, Cannon GW, Reimold A. Associations of disease activity and treatments with mortality in men with rheumatoid arthritis: results from the VARA registry. Rheumatology (Oxford). 2011 Jan;50(1):101-9.

Mikuls TR, Kazi S, Cipher Det al. The association of race and ethnicity with disease expression in male US veterans with rheumatoid arthritis. J Rheum. 2007 July;34(7):1480-1484

Najarian RM, Sullivan LM, Kannel WB, et al. Metabolic syndrome compared with type 2 diabetes mellitus as a risk factor for stroke: the Framingham Offspring Study. Arch Intern Med. 2006;166:106-11.

Ouchi N, Parker JL, Lugus JJ, Walsh K. Adipokines in inflammation and metabolic disease. Nat Rev Immunol 2011;11:85-97.

Pandya, P, Mathur S, Callahan P, et al. The prevalence of metabolic syndrome in veterans with chronic hepatitis C virus. DDW, May 21-24, 2006, Los Angeles.

Prevoo ML, Van 't Hof MA, Kuper HH, van Leeuwen MA, et al. Modified disease activity scores that include twenty-eight-joint counts. Development and validation in a prospective longitudinal study of patients with rheumatoid arthritis. Arthritis Rheum. 1995 Jan;38(1):44-48.

Rodriguez-Pla A, Giles JT, Blumenthal RS, Post W, Szklo M, Petri M, Gelber AC, Detrano R, Bathon JM. Decreased Prevalence of the Metabolic Syndrome in Rheumatoid Arthritis. Arthritis Rheum 2007; 56(9S):S416. 
Stavropoulos-Kalinoglou A, Metsios GS, Koutedakis Y, Nevill AM, Douglas KM, Jamurtas A, van Zanten JJ, Labib M, Kitas GD. Redefining overweight and obesity in rheumatoid arthritis patients. Ann Rheum Dis. 2007 Oct;66(10):1316-21

Steven M. Comparison of Quality of Care for Patients in the Veterans Health Administration and Patients in a National Sample. Ann Intern Med. 2004 Dec;141:938-945.

Stevens RJ, Douglas KM, Saratzis AN, et al. Inflammation and atherosclerosis in rheumatoid arthritis. Expert Rev Mol Med. 2005 May 6;7(7):1-24.

World Health Organization. Definition, Diagnosis and Classification of Diabetes Mellitus and Its Complications: Report of a WHO Consultation. Geneva: World Health Organization. 1999. 


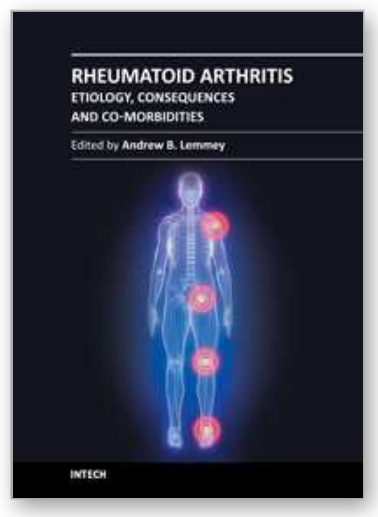

\author{
Rheumatoid Arthritis - Etiology, Consequences and Co-Morbidities \\ Edited by Dr. Andrew Lemmey
}

ISBN 978-953-307-847-2

Hard cover, 304 pages

Publisher InTech

Published online 11, January, 2012

Published in print edition January, 2012

The purpose of this book is to provide up-to-date, interesting, and thought-provoking perspectives on various aspects of research into current and potential treatments for rheumatoid arthritis (RA). This book features 16 chapters, with contributions from numerous countries (e.g. UK, USA, Japan, Sweden, Spain, Ireland, Poland, Norway), including chapters from internationally recognized leaders in rheumatology research. It is anticipated that Rheumatoid Arthritis - Etiology, Consequences and Co-Morbidities will provide both a useful reference and source of potential areas of investigation for research scientists working in the field of RA and other inflammatory arthropathies.

\title{
How to reference
}

In order to correctly reference this scholarly work, feel free to copy and paste the following:

G.S. Kerr, I. Sabahi, J.S. Richards, T.R. Mikuls, B.V. Rangan, A. Reimold, G.W. Cannon, D. Johnson and L. Caplan (2012). Association of Cardiovascular Disease with the Metabolic Syndrome in a Predominantly Male Cohort with Rheumatoid Arthritis, Rheumatoid Arthritis - Etiology, Consequences and Co-Morbidities, Dr. Andrew Lemmey (Ed.), ISBN: 978-953-307-847-2, InTech, Available from: http://www.intechopen.com/books/rheumatoid-arthritis-etiology-consequences-and-co-morbidities/associationof-cardiovascular-disease-with-the-metabolic-syndrome-in-a-predominantly-male-cohort-wit

\section{INTECH}

open science | open minds

\author{
InTech Europe \\ University Campus STeP Ri \\ Slavka Krautzeka 83/A \\ 51000 Rijeka, Croatia \\ Phone: +385 (51) 770447 \\ Fax: +385 (51) 686166 \\ www.intechopen.com
}

\author{
InTech China \\ Unit 405, Office Block, Hotel Equatorial Shanghai \\ No.65, Yan An Road (West), Shanghai, 200040, China \\ 中国上海市延安西路65号上海国际贵都大饭店办公楼 405 单元 \\ Phone: +86-21-62489820 \\ Fax: +86-21-62489821
}


(C) 2012 The Author(s). Licensee IntechOpen. This is an open access article distributed under the terms of the Creative Commons Attribution 3.0 License, which permits unrestricted use, distribution, and reproduction in any medium, provided the original work is properly cited. 